\title{
Ocular complications of ulcerative colitis
}

\author{
F. A. BILlSON, F. T. DE DOMBAL, G. WATKINSON, AND J. C. GOLIGHER \\ From the Ophthalmic Department and the Colitis Clinic of The General Infirmary at Leeds
}

EDITORIAL COMMENT This study showed that 17 out of 465 patients, i.e., $3 \cdot 6 \%$, had ocular complications. These were always associated with at least one other systemic complication and all the patients had joint symptoms. It seems likely that the greater use of corticosteroids may reduce the incidence of eye complications, especially of uveitis.

Ocular disease arising in association with ulcerative colitis is rare. It was first described by Crohn (1925) who recorded the occurrence of corneal inflammation with conjunctivitis in two patients with ulcerative colitis. Since then, most reports have been confined to a few isolated cases (Bargen, 1929; Hurst, 1935; Rice-Oxley and Truelove, 1950; Cullinan and MacDougall, 1957; Hightower, Broders, Haines, McKenney, and Sommer, 1958; Ellis and Gentry, 1964; Thorpe, 1966); although Edwards and Truelove (1964), and Wright, Lumsden, Luntz, Sevel, and Truelove (1965) have recently described patients with colitis and eye complaints in more detail.

The present paper describes in detail the eye lesions which were found among a group of 465 patients with ulcerative colitis. An analysis is presented of the types of eye lesion found among the patients, and an attempt is made to relate the development of eye lesions to the clinical course of colitis.

\section{CLINICAL MATERIAL AND METHODS}

The ocular lesions described in this paper were recorded during a survey of 465 patients with ulcerative colitis who presented to a combined medicosurgical clinic in Leeds during the period 1952-63. The follow-up and life histories of these 465 patients have been previously described (Watts, de Dombal, Watkinson, and Goligher, 1966a, b). This survey was based on the study of personally compiled case histories, and in addition during the latter half of 1963, all but eight of the surviving patients were personally interviewed and examined.

Attacks of colitis were graded according to the criteria of Truelove and Witts (1955). The extent of colitis was assessed by means of repeated sigmoidoscopy and barium enema examinations. We have made use of the concept of a 'patient year', that is to say, one year of observed follow-up of an individual patient, during our long-term follow-up studies
(Watts et al., 1966b), and we have also used this concept in the present paper to relate the development of eye lesions to the clinical course of colitis.

Every patient who was found to have ocular symptoms at examination, or who complained of symptoms, past or present, referable to the eyes, was also examined in detail by an ophthalmic surgeon (F. A. Billson). A detailed history of the ocular complaint was obtained, and the following special investigations were performed: (1) refraction; (2) slit lamp examination of the anterior segment (including gonioscopy before mydriasis); (3) ophthalmoscopy; (4) the ocular tension was recorded in any case with evidence of uveitis; (5) bacteriological studies were also performed in the majority of patients with episcleritis; in no case was a specific bacteriological cause for the lesion demonstrated; (6) fluorescein $2 \%$ and Rose Bengal were inserted in all cases of superficial inflammation when seen in the active phase.

\section{FINDINGS}

Among the group of 465 patients with ulcerative colitis, 17 patients $(3.6 \%)$ were found to be suffering from eye lesions. These complications occurred in $3.7 \%$ of the 275 females surveyed and in $2.9 \%$ of 190 males surveyed. The mean age at which eye lesions developed was 35 years. The mean age of patients at time of onset of colitis was 31 years.

The nature of the eye lesions which were found during this survey is shown in Table I. For the purpose of this report, episcleritis has been defined as an inflammatory condition involving the episcleral tissues, usually segmental and bilateral in distribution, associated with variable discomfort and unassociated with purulent discharge. When so defined, episcleritis occurred in seven of our 465 patients $(1.5 \%)$. Evidence of iritis was obtained on the basis of typical symptoms, and on personal observations of at least three of the following characteristics: (1) iridospasm; (2) protein flare in the anterior 
chamber; (3) cells in the anterior chamber; (4) keratic precipitates; (5) atrophy of the iris; (6) ectropion of uveal pigment; (7) evidence of anterior or posterior synechiae, and (8) old pigment deposits on the lens. Five patients $(1 \cdot 1 \%)$ were found to have iritis as defined in this way.

TABLE I

NATURE AND FREQUENCY OF EYE LESIONS IN A GROUP OF 465 COLITIC PATIENTS

Nature of Eye Lesion

No. of Patients

Episcleritis

Iritis

Blepharo-keratitis

Interstitial keratitis

Choroiditis

Dacryostenosis

Total

7
5
2
1
1
1
17

Less common findings were: superficial keratitis associated with blepharitis (two patients); and interstitial keratitis (one patient). One further patient was found to have choroiditis and one patient dacryostenosis.

The corrected vision of all but two of the patients with eye disease was $6 / 6$ when finally tested in the quiescent phase. Of the two with poor vision, one had chronic disseminated choroiditis, and the other had interstitial keratitis of luetic origin.

RELATIONSHIP OF EYE LESIONS TO THE CLINICAL COURSE OF COLITIS

Severity Figure 1 shows that the incidence of development of eye lesions was highest $(3.8 \%)$ in patient years during which a severe attack of colitis had taken place. By contrast, no eye lesions developed

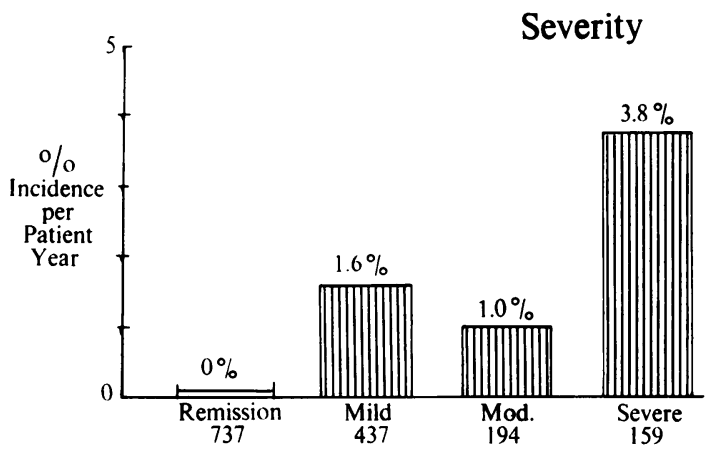

FIG. 1. Relationship between the incidence of eye lesions in each patient year, and the maximum severity of colitis in that year.

(Figures below categories indicate number of patient years analysed in each category.) during years in which the patient's colitis remained in remission. Moreover, we have investigated these 'severe attack years' in more detail, and have found that in almost every case the development of eye complications was associated with a specific severe attack of colitis during that year.

Extent of colitis This appeared to have much less relationship to the development of eye lesions. Figure 2 shows that there were 371 patient years in

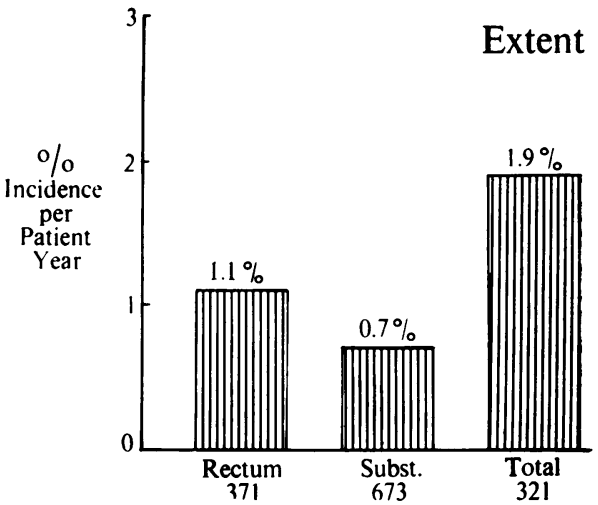

FIG. 2. Relationship between incidence of eye lesions and the extent of colitis in each patient year.

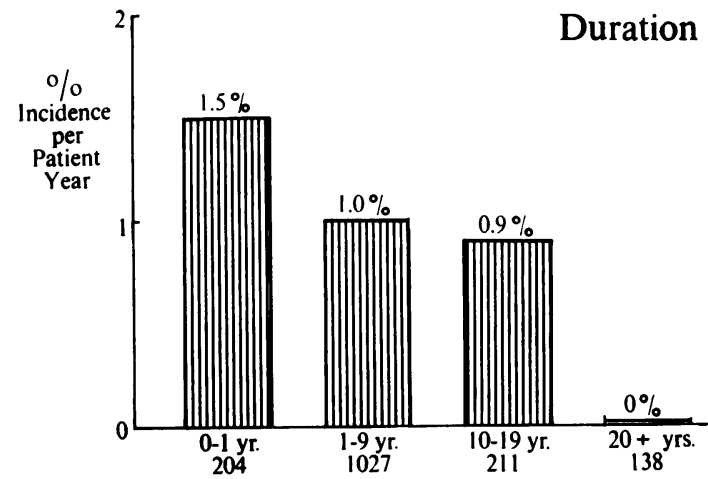

FIG. 3. The relationship between incidence of eye lesions and the duration of colitic symptoms.

which the disease remained restricted to the rectum, and eye lesions developed in four of these patient years $(1 \cdot 1 \%)$. Such lesions also developed during six of the 321 patient years $(1.9 \%)$ in which the whole colon and rectum were involved.

Duration of colitic symptoms Figure 3 shows that eye lesions developed most commonly during the early stages of colitis. They were most frequently observed during the first year of colitic symptoms, being found in three of 204 patients $(1.5 \%)$. The mean duration of colitic symptoms at the time at 
which eye complications developed was four years.

Association with other complications of colitis Only two of the 17 patients with colitis and eye disease escaped without at least one other systemic complication. Four of the patients were found to have associated skin complaints (two patients had pyoderma, one had erythema nodosum, and one had leg ulcers). Eight of the 17 patients also suffered from arthritis, in each case a true colitic arthritis as defined by Wright and Watkinson (1965a), with negative latex and sheep cell agglutination tests; three of these eight patients were also found to have ankylosing spondylitis (Wright and Watkinson, 1965b). Six patients with eye disease also showed evidence of ulceration of the mouth.

TREATMENT AND OUTCOME OF EYE LESIONS In no case did the eye condition influence the decision for colonic surgery. However, eight of the 17 patients required surgical treatment for other reasons, and in all eight cases the eye lesions cleared shortly after operation. In the remaining nine patients the colitis was treated conservatively; in two of these nine patients the eye lesions persisted up to the time of review. However, in a further three patients, the eye lesions cleared up for a short time, only to recur at a later date.

Local treatment of episcleritis and iritis included the use of corticosteroids. All cases of episcleritis responded to treatment with guttae Predsol 0.5\% q.d.s. In the cases of iritis, the instillation of Predsol drops was usually at more frequent intervals, often hourly. Severe cases of iritis were also treated with mydriatics, and subconjunctival injections of cortisone and mydricaine; in one particularly severe case Prednisolone was employed systemically.

\section{DISCUSSION}

During the First World War eye lesions were well recognized to occur in some of the combatants suffering from the specific dysenteries (Crouzon, 1916; Maxwell and Kiep, 1918; Graham, 1919).

When Crohn described ocular lesions in association with ulcerative colitis in 1925 he ascribed them to vitamin deficiency resulting from poor diet and decreased intestinal absorption.

Early reports in the literature of eye complications in ulcerative colitis were sporadic, and usually confined to so few cases that it might be argued they were entirely coincidental. But in recent reports, Edwards and Truelove (1964), Ellis and Gentry (1964), and Wright et al. (1965) have examined the association between eye lesions and ulcerative colitis in much greater detail. In this respect the paper by
Wright et al. (1965) has been particularly valuable. These authors investigated a group of 144 patients with ulcerative colitis, and found that no less than 17 patients $(11.8 \%$ of the total group) had objective evidence of past or present uveitis. This incidence of uveitis in their colitic patients was significantly higher than the incidence in a control group who were matched for age and sex. Patients with evidence of uveitis also had a higher incidence of sacro-iliitis, and these complications chiefly occurred in elderly patients, in females, and in patients who had a history of ulcerative colitis dating back for more than 10 years.

In the present series of 465 colitic patients, objective evidence of eye disease was found in only 17 . Moreover, in five of these patients the eye disease was considered to be unrelated to the colitis. In one case, an interstitial keratitis was due to congenital syphilis. Another patient suffered a deterioration of vision due to choroiditis some 20 years before the onset of colitic symptoms. There were two cases of blepharo-keratitis; one was related to acne rosacea (having the features of a true rosacea keratitis, with deep and superficial corneal infiltrates and also a sector of rosacea pannus); whilst the other was a case of seborrhoeic blepharitis with accompanying superficial keratitis. One further patient was found to have a stenosis of the nasolacrimal duct.

In the remaining 12 cases, we believe that the eye disease was a genuine complication of the colitis. This eye disease consisted in five patients of iritis and in seven patients of episcleritis. Admittedly, the prevalence of these eye lesions among the general population in this country has not yet been fully worked out but Darrell (Darrell, Wagener; and Kurland, 1962) has estimated the general prevalence of iritis in the United States as being only one or two per thousand persons. We are impressed moreover, by the association between the development of these eye lesions and attacks of colitis (Fig. 1).

When considering the aetiology of these eye lesions, it must be said that the evidence for a dietary cause in our patients was most unconvincing. Even the clinical appearances of superficial keratitis and blepharo-keratitis were far from being suggestive of a vitamin deficiency. A bacterial cause seems improbable as smears and cultures taken in our series of patients were in all cases negative. The absence of follicular hyperplasia in the conjunctiva, and the prompt resolution of the lesions after the exhibition of steroid weighed against a viral cause, but we must admit that search for a virus was not undertaken.

RELATIONSHIP TO CLINICAL COURSE OF COLITIS It was impossible to compare the development of eye complications with the clinical course of colitis in 
many of the early published reports, because the number of patients involved were extremely small. However, Edwards and Truelove (1964), reporting a series of 47 such patients, claimed that there was a tendency for ocular lesions to flare up in association with attacks of colitis. Conversely, Ellis and Gentry (1964) claimed that the development of eye lesions does not parallel the severity of colitic symptoms.

More recently, Wright et al. (1965) investigating patients with uveitis, found that there was a strong association between clinical attacks of colitis and the development of eye lesions. These authors also found that eye lesions were far more common among patients with longstanding colitis. Nearly one third of their patients with a history of colitic symptoms of 10 or more years also had evidence of past or present anterior uveitis. A significant proportion of this group of patients also showed radiological evidence of sacro-iliac joint changes.

The data from our own series suggest that there is a definite association between attacks of colitis (and in particular severe attacks) and the development of eye lesions. In our group of patients, the incidence of eye lesions was highest $(3.8 \%)$ during patient years in which a severe attack took place. In addition we have also noticed an association between eye lesions and joint changes in our patients. Every one of our patients suffering from iritis also suffered from a true colitic arthritis, and three of these five patients suffered from ankylosing spondylitis as well.

However, one clear point of difference emerges when our own data are compared with those of Wright et al. (1965). In a total period of follow-up of 138 patient years in patients with longstanding colitis we have failed to find evidence of a single eye lesion, whereas Wright et al. (1965) found such lesions to be common in the longstanding colitic patient.

At first sight these conflicting data appear to be irreconcilable. However, it must be remembered that we have only noted symptomatic lesions, and have excluded lesions which occurred before the period of observed follow-up. Thus, despite the long history of colitis in our patients, we have only noted the development of eye lesions during the last 10 years, at a time during which we have made use of corticosteroid therapy on a large scale. It may be that the high incidence of eye lesions noted by Wright $e t$ al. (1965) in their longstanding group is due to lesions which had occurred 10 or more years ago, before corticosteroids were widely used to control attacks of colitis. It is interesting to speculate further that the low incidence of uveitis noted in the present series may also have been due to our treatment of severe attacks of colitis with large doses of systemic steroids, a form of treatment which is, of course, highly effective for uveitis.
ULCERATIVE COLITIS AND REITER'S DISEASE The combination of ocular lesions, arthritis, and diarrhoea also occurs in the 'diarrhoeal form' of Reiter's disease. Iritis is a common complication of Reiter's disease, and its development is closely associated with sacro-iliitis and an atypical spondylitis (Oates and Young, 1959; Csonka, 1959); and certainly this is a point of similarity with our own cases. However, it should be stressed that all of our cases had unequivocal sigmoidoscopic and radiological evidence of ulcerative colitis. All five patients with iritis and spondylitis were female, a most unusual sex distribution for Reiter's disease. Moreover, all of these patients suffered from repeated bouts of diarrhoea, again a point of dissimilarity with the diarrhoeal form of Reiter's disease.

The differential diagnosis is thus usually readily resolved in such patients. However, in any such patient with iritis, arthritis, and diarrhoea, where the diarrhoea recurs or is a prominent feature of the symptom complex, clearly investigation to exclude ulcerative colitis by means of barium enema and sigmoidoscopy must be carried out.

\section{SUMMARY}

During a survey of 465 patients with ulcerative colitis 17 patients were found to have ocular complications of their colitis. There were seven cases of episcleritis and five of iritis. Females were more frequently affected than males.

Eye lesions developed in association with attacks of colitis, particularly with severe attacks; and the presence of an eye lesion was almost always associated with at least one other of the systemic manifestations of colitis. Every one of the patients with iritis also suffered from joint symptoms.

The low incidence of iritis in the present group of patients may be due to the widespread use of steroids in treating severe attacks of ulcerative colitis.

The symptomatology of the diarrhoeal form of Reiter's disease is compared with the clinical picture in the present group of colitic patients with multiple systemic complications. Specific recommendations are made for patients where the differential diagnosis is in doubt.

We are grateful to Mr. John Foster, consultant ophthalmic surgeon, The General Infirmary at Leeds, and to Dr. J. A. Hancock, consultant venereologist, The General Infirmary at Leeds, for their helpful advice and criticism in the preparation of this paper.

\section{REFERENCES}

Bargen, J. A. (1929). Complications and sequelae of chronic ulcerative colitis. Ann. intern. Med., 3, 335-352.

Crohn, B. B. (1925). Ocular lesions complicating ulcerative colitis. Amer. J. med. Sci., 169, 260-267. 
Crouzon, O. (1916). La conjonctivite et le rhumatisme dysentériques. Bull. Soc. méd. Hôp. Paris, 40, 1926-8.

Csonka, G. W. (1959). Significance of sacro-iliitis in Reiter's disease. Brit. J. vener. Dis., 35, 77-80.

Cullinan, E. R., and MacDougall, I. P. (1957). The natural history of ulcerative colitis. Lancet, 1, 487-9.

Darrell, R. W., Wagener, H. P., and Kurland, L. T. (1962). Epidemiology of uveitis: incidence and prevalence in a small urban community. Arch. Ophthal., 68, 502-14.

Edwards, F. C., and Truelove, S. C. (1964). The course and prognosis of ulcerative colitis. Part III. Complications. Gut, 5, 1-15.

Ellis, P. P., and Gentry, J. H. (1964). Ocular complications of ulcerative colitis. Amer. J. Ophthal., 58, 779-85.

Graham, G. (1919). Arthritis in dysentery: its causation, prognosis and treatment. Proc. roy. Soc. Med., 13, (Sect. med.), 23-42.

Hightower, N. C., Jr., Broders, A. C., Jr., Haines, R. D., McKenney, J. F., and Sommer, A. W. (1958). Chronic ulcerative colitis. II. Complications. Amer. J. dig. Dis., 3, 861-76.

Hurst, A. F. (1935). Prognosis of ulcerative coitis. Lancet, 2, 1194-96.

Maxwell, E. M., and Kiep, W. H. (1918). Notes on 6 cases of iritis and cyclitis occurring in dysenteric patients. Brit. J. Ophthal., 2, 71-79.

Oates, J. K., and Young, A. C. (1959). Sacro ilitits in Reiter's disease. Brit. med. J., 1, 1013-5.

Rice-Oxley, J. M., and Truelove, S. (1950). Complications of ulcerative colitis. Lancet, 1, 607-11.

Thorpe, G. J. (1966). Arthritis, iridocyclitis and ulcerative colitis. Brit. J. clin. Pract, 20, 205-8.

Truelove, S. C., and Witts, L. J. (1955). Cortisone in ulcerative colitis. Brit. med. J., 2, 1041-8.

Watts, J. McK., de Dombal, F. T., Watkinson, G., and Goligher, J. C. (1966a). Early course of ulcerative colitis. Gut, 7, 16-31.

,,---1 - (1966b). The long-term prognosis of ulcerative colitis. Brit. med. J., 1, 1447-53.

Wright, V., and Watkinson, G. (1965a). The arthritis of ulcerative colitis. Ibid., 2, 670-5.

(1965b). Sacri-ileitis and ulcerative colitis. Ibid., 2, 675-80.

Wright, R, Lumsden, K., Luntz, M. H., Sevel, D., and Truelove, S. C. (1965). Abnormalities of the sacro-iliac joints and uveitis in ulcerative colitis. Quart. J. Med., 34, 229-236. 